Acta Universitatis SAPIENTIAE

Agriculture And EnVIRONMENT, 13 (2021) 88-99

DOI: 10.2478/ausae-2021-0008

\title{
Evolution of quality parameters of different lettuce (Lactuca sativa L.) varieties under unheated plastic tunnel
}

\author{
Ágota KOVÁCSNÉ MADAR, ${ }^{1}$ Mária TAKÁCSNÉ HÁJOS²
}

${ }^{1,2}$ University of Debrecen, Faculty of Agricultural and Food Sciences and Enviromental Management, Institute of Horticultural Science, 138 Böszörményi St., H-4032 Debrecen, Hungary; e-mail: ${ }^{1}$ madar.agota@agr.unideb.hu; ${ }^{2}$ hajos@agr.unideb.hu

Manuscript received 22 July 2021; revised 30 August 2021; accepted 12 September 2021

\begin{abstract}
The plastic tunnel can ensure a positive effect on the yield and quality of vegetables. In our experiment, we evaluated the following types and varieties of lettuce - heading type ('Great Lakes 659', 'King of May'), non-heading type ('Lollo Rossa', 'Lollo Bionda'), and cos type ('Romaine lettuce'). The highest head weight was detected in 'Great Lakes 659' (373.97 g plant $^{-1}$ ) and 'Romaine lettuce' (266.79 g plant $^{-1}$ ) under an unheated plastic tunnel in springtime. Higher nitrate content (565.0 $\mathrm{mg} \mathrm{kg}^{-1}$ ) was measured for 'cos lettuce', while lower values (425.50 mg kg-1) were measured for 'Lollo Bionda'. Among the varieties, one of the highest dry matter content was also measured for 'Great Lakes 659' (8.52\%). According to our results for lettuce production, 'Great Lakes 659' was detected as having a higher yield and dry matter content and a lower nitrate accumulation.
\end{abstract}

Keywords: spring, yield, nitrate, SPAD, NDVI

\section{Introduction}

Among the leafy vegetables, lettuce (Lactuca sativa L.) is the most important commercial vegetable and has the highest consumption in the world. Due to its high use in fast food, it is important for the grower to be able to produce lettuce of good quality with high yields [1]. The worldwide processing of lettuce and chicory is around 27 million tons, $73.7 \%$ of which being produced in Asia and 9.7\% in Europe. In addition, lettuce has been recognized as a major food for its vitamin, mineral, and bioactive compounds such as phytochemicals (phenols, flavonoids, and carotenoids) [2]. Therefore, it can be an important component of a balanced diet. However, lettuce can accumulate a rather high amount of nitrate. This process 
depends on the nitrate content of the soil, light intensity during the growing period, and genetic factors [3]. European countries have set acceptable levels for nitrate accumulation in some vegetables (EU Limits for Nitrate, from Commission Regulation (EU) No 1258/2011). The maximum nitrate accumulation limits in fresh lettuce (Lactuca sativa L.) grown under cover and in open field, except for iceberg lettuce, are the following: in the autumn (harvested from 1 October to 31 March) - for lettuce grown under cover 5,000 mg NO $\mathrm{kg}^{-1}$ and in the open air 4,000 mg NO $\mathrm{kg}^{-1}$; in the summer (harvested from 1 April to 30 September) - for lettuce grown under cover 4,000 mg NO $\mathrm{kg}^{-1}$ and in the open air 3,000 $\mathrm{mg} \mathrm{NO}_{3} \mathrm{~kg}^{-1}$; for the iceberg lettuce type grown under cover $2,500 \mathrm{mg} \mathrm{NO}_{3} \mathrm{~kg}^{-1}$ while in the open air 2,000 $\mathrm{mg} \mathrm{NO}_{3} \mathrm{~kg}^{-1}$ [4]. In addition, a positive correlation between chlorophyll and nitrate content in vegetables has been reported in some studies. Based on this relationship, it is possible to determine the nitrogen status of plants using nondestructive chlorophyll measuring instruments [5]. Some devices are suitable for measuring the relative chlorophyll content such as the Minolta SPAD-502 device, with which we can determine this parameter quickly and without destruction [6].

Determining the time of harvest is an important factor because early harvest reduces yield and quality [7]. A wide range of physical parameters of the plants is used to estimate the degree of ripeness: head length, head width, diameter, and compactness. These parameters are used as a general maturation index [8].

In some studies, the measurement of NDVI has been used to estimate plant biomass [9].

The leafy head is a major feature of leafy vegetables and consists of curved leaves and these shapes' ratio of diameter and height of the head (shape index) [10].

Our aim was to evaluate different lettuce species in spring cultivation and to recommend the appropriate species based on their quality properties such as head weight, shape index, nitrate accumulation, or dry matter content.

\section{Materials and methods}

The experiment was conducted in the Botanical and Exhibition Garden of the Farm and Regional Research Institute at the University of Debrecen, under an unheated plastic tunnel (in the springs of 2019 and 2020), on limestone chernozem soil.

For the evaluation, we examined two heading lettuces, i.e. crisphead ('Great Lakes 659') and butterhead ('King of May'). We also evaluated non-heading lettuces ('Lollo Bionda', 'Lollo Rossa') and cos lettuce ('Romaine lettuce') in two growing seasons.

The sowing was performed in 84-cell trays on 9 March 2019 and 12 March 2020. During these periods, Previcur ${ }^{\circledR}$ Energy was applied at a dose of $3 \mathrm{ml} \mathrm{m}^{-2}$ against damping off. In addition, it should be noted that conventional (non-coated) seed was used in the first year and pelleted (coated) seed in the second year. 
The experiment design was a randomized block design with four replications. The 5-6-leaf seedlings were planted out in a $25 \times 25 \mathrm{~cm}$ space on 9 April 2019 and 10 April 2020 under the unheated plastic tunnel. Three times during the vegetation period, Ferticare (24:8:16 + 3.8 MgO + microelement) was used in $0.75 \%$ concentration. In both years, the harvest was carried out two months after the planting date (23 May 2019; 21 May 2020). The measurement was realized for the following parameters: leaf shape index (length/width), head shape index (height/diameter), and closing of the base on the scale 1-5 (1- open ... 5- completely closed). Furthermore, we measured the head weight (g per plant) and stem length (cm).

Measurement of photosynthesis activity:

- SPAD value (Minolta SPAD-502) - easy non-destructive measurement of the chlorophyll content of plant leaves without damaging the leaves;

- NDVI value (Green Seeker Model 505) - can be used to monitor crop growth and development.

Laboratory measurements:

- Total dry matter content (\%) - it was determined after drying at $105{ }^{\circ} \mathrm{C}$ until constant weight.

- Nitrate content ( $\mathrm{mg} \mathrm{kg}^{-1}$ ) - MSZ EN 12014-7:1999. Determination of nitrate and/ or nitrite content - Part 7: continuous flow method for the determination of nitrate content of vegetables and vegetable products after Cadmium reduction.

\section{Statistical analysis}

Statistical analyses were performed using SPSS software (version 25). The data were submitted for analysis of variance (ANOVA). The differences between the data at a significance level of $5 \%(0.05)$ were determined by post-hoc Tukey's test $(\mathrm{n}=20)$. Pearson's correlation coefficient between some pairs of data was also calculated. The correlation was significant at $\mathrm{p} \leq 0.05$ and $\mathrm{p} \leq 0.01$ levels (2-tailed).

Temperature and humidity data were measured at two characteristic times of the growing period, in the morning (between 8 and 9 a.m.) and in the afternoon (between 1 and 2 p.m.) in order to check the lower and higher temperature intervals of the active photoperiodic phase. Nearly the same temperature values were measured at the two-assimilation period in 2019 and 2020, as shown in Figure 1.

In the first year, the temperature was $16.53 \pm 5.88^{\circ} \mathrm{C}$ in the morning and $27.48 \pm$ $4.23^{\circ} \mathrm{C}$ in the afternoon. In the second year, a slightly higher value was measured in the morning $\left(16.99 \pm 5.85^{\circ} \mathrm{C}\right)$ and in the afternoon $\left(28.82 \pm 4.42^{\circ} \mathrm{C}\right)$. Furthermore, in the first season, we measured a little higher humidity (a.m.: $64.67 \pm 9.27 \%$; p.m.: $41.56 \pm 7.99 \%$ ) than in the second year (a.m.: $56.76 \pm 12.75 \%$; p.m.: $34.29 \pm$ $9.42 \%)$. The optimum relative humidity is $70-75 \%$ for lettuce - at these values, the 
fastest growth rate is achieved. In our experiment, the lower humidity influenced the lettuce development, by slowing it. Comparing the two growing seasons: in 2019, there was less radiation $\left(139.74 \pm 58.86 \mathrm{~W} \mathrm{~m}^{-2}\right)$ than in 2020 (176.97 \pm 49.96 $\mathrm{W} \mathrm{m}^{-2}$ ), as shown in Figure 2. In the second year, higher light radiation may have had a positive effect on lettuce development. In general, under better light conditions, lettuce improvement was faster.

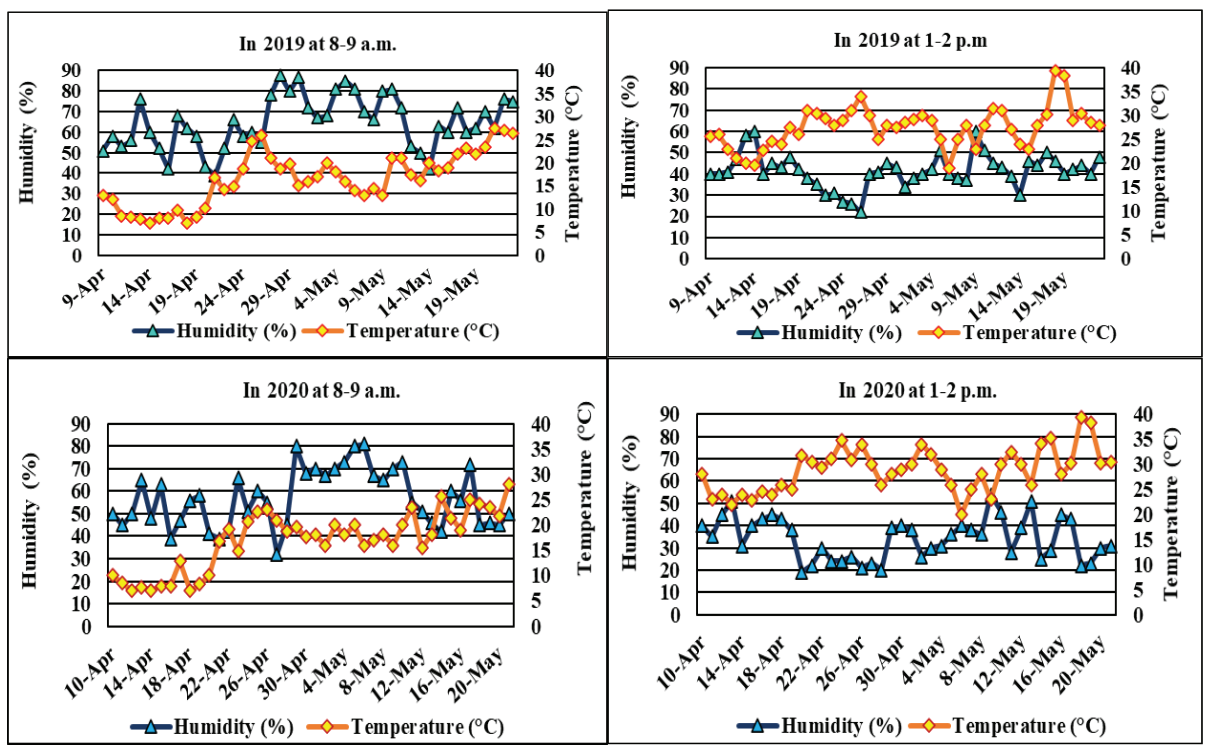

Figure 1. Temperature $\left({ }^{\circ} \mathrm{C}\right)$ and humidity $(\%)$ data during the growing season in 2019 and 2020

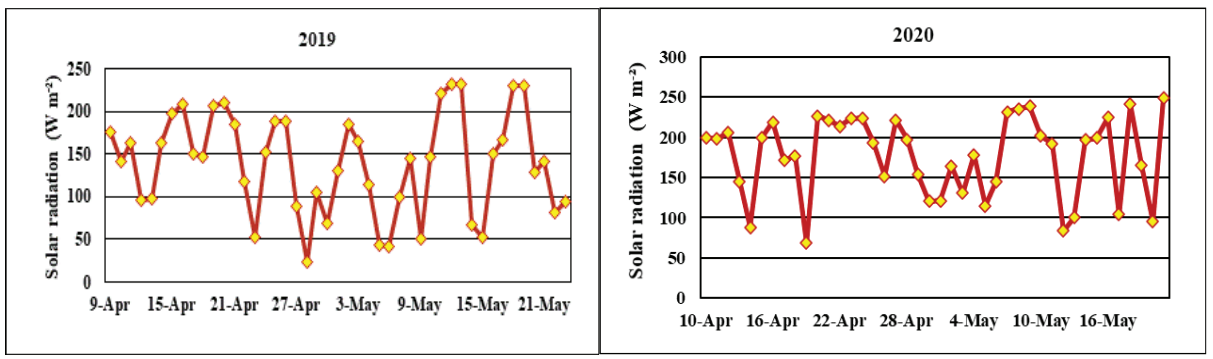

Figure 2. Solar radiation $\left(\mathrm{W} \mathrm{m}^{-2}\right)$ during the growing seasons 


\section{Results and discussions}

One of the most important quality parameters of the fresh market is the head weight of the lettuce. The length of the inner stem can determine the number of leaves, which also affects the head weight.

Based on the data of the two years, we measured much higher head weight and stem length values in the second growing season (Figure 3) due to the pelleted seeds, which resulted improved transplants. In addition, during this period, the light conditions were more favourable, which promoted better yield and head weight value of the lettuce.

Basically, in 2019, a smaller stem length led to a smaller head weight, while in 2020 a larger stem length led to a higher head weight. Furthermore, concerning the average of the two years, we found a strong correlation $(r=0.719)$ relationship between head weight and stem length.

One study reported that butterhead lettuce harvested at the optimal maturity stage had a fresh weight of 200-300 $\mathrm{g} \mathrm{head}^{-1}$ [8]. In our experiment, this head weight was realized in both years. The highest head weight was measured among the heading form varieties of 'Great Lakes 659', which was statistically proved.

Among the loose leaf varieties, we found higher head weight (178.56 \pm 12.71 g plant $^{-1} ; 276.12 \pm 23.04$ g plant $\left.^{-1}\right)$ in 'Lollo Bionda'. Researchers measured the highest leaf weight (12.98 and $15.91 \mathrm{~g}$ ) on days 107 and 114 after transplanting also for iceberg lettuce when compared to butterhead (6.1 and $15.33 \mathrm{~g}$ ) and romaine lettuce (5.34 and $5.25 \mathrm{~g}$ ) in autumn greenhouse cultivation [7].

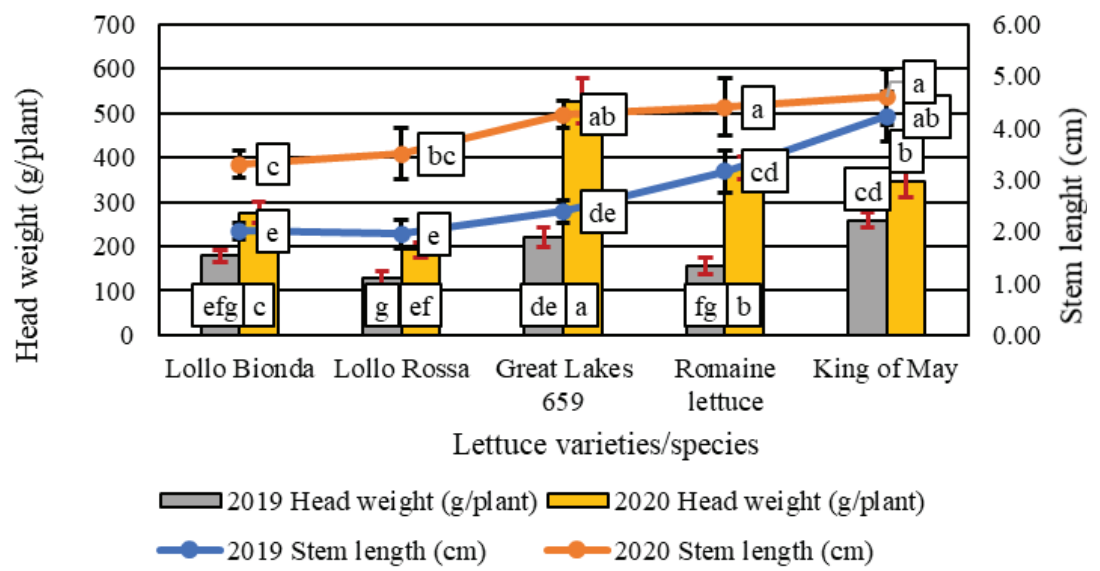

Note: There is no significant difference between the lettuce varieties/types marked with the same letter according to Tukey's test $(\mathrm{P} \leq 0.05)$.

Figure 3. Relationship between lettuce head weight (g/plant) and stem length (cm) in 2019 and 2020 
The lettuce with a closed base is mainly resistant to Botrytis sp. and sclerotic infection. These pathogenic fungi infect hundreds of plant species around the world. Sclerotia penetrate the plant and infect mostly through the lower senescent leaves in contact with the soil. These fungi attack the lettuce at any stage of development and in all parts of the plant. These pathogens cause great problems in the world year after year, depending on the weather conditions and host plant. Thus, growers often use large amounts of fungicide treatment against diseases [11].

The closing of the base of the lettuce was evaluated on a scale of 1 to 5 . One (1) indicates the open and five (5) the fully closed base. Basically, in the second year, we found a well-closed base part for each lettuce, as shown in Fig 4. During the experiment, it was established that the loose leaf type of lettuce ('Lollo Bionda, 'Lollo Rossa') had a lower value for the closing of base than the heading type varieties ('Great Lakes 659', 'Romaine lettuce', 'King of May'). This result was statistically proved in the two experimental years. The higher value of this morphological parameter (closing of base) is favourable because these varieties are less sensitive to soil-borne diseases.

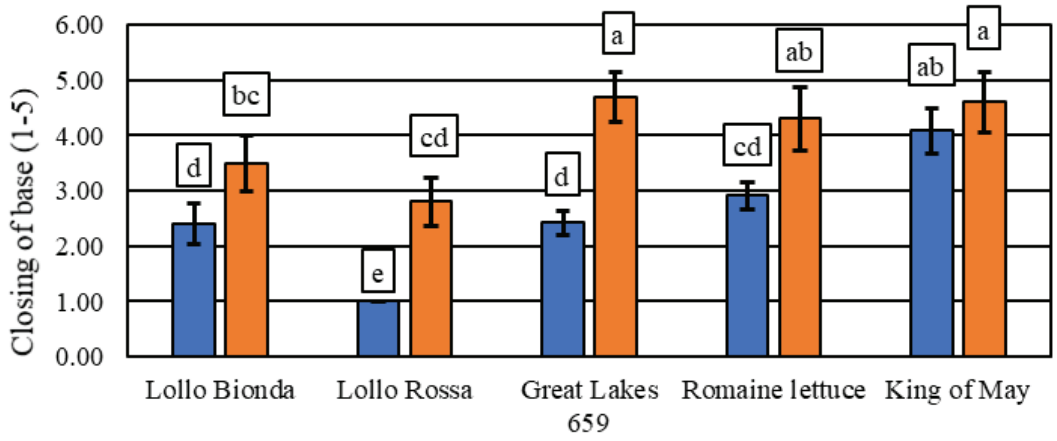

Lettuce varieties/species

$\square 2019 \square 2020$

Note: There is no significant difference between the lettuce varieties/types marked with the same letter according to Tukey's test $(\mathrm{P} \leq 0.05)$.

Figure 4 . The closing of the base part of the lettuce (1-5 scale) in 2019 and 2020

In general, lettuce should be harvested when the heads are well-formed and firm. The lettuce is graded by size and firmness, while non-heading lettuce is classified only by size [12]. The shape index (height/diameter) can determine the possible contact of the lower leaves with the soil. Varieties with upright leaves are more suitable for growing because they can be less infected by fungal diseases. In cos lettuce ('Romaine lettuce'), a longer head and leaf shape index was detected in both growing seasons (Figure 5). The 'Lollo Bionda' formed the typical flat-round head $(0.61 \pm 0.01)$. 
Researchers had detected that temperature and light intensity can determine the shape index. The experiment with the iceberg lettuce cv. 'Adam' proved that lower temperature and light intensity reduced the leaf shape index [13].

In our experiment, we measured a smaller leaf shape index $(0.70 \pm 0.03)$ under higher irradiation, while a larger leaf shape index (1.07 \pm 0.05$)$ was detected under lower irradiation for the iceberg lettuce cv 'Great Lakes 659'.

A strong correlation relationship $(\mathrm{r}=0.862)$ was observed between the measured parameters concerning the average of the two years. Overall, a more compact head was found in the second year.

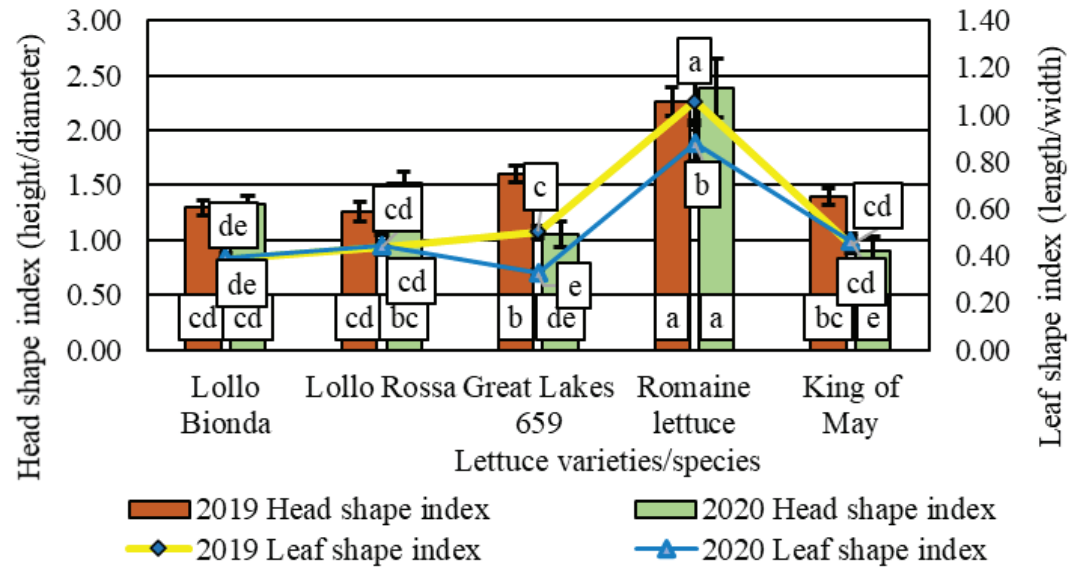

Note: There is no significant difference between the lettuce varieties/types marked with the same letter according to Tukey's test $(\mathrm{P} \leq 0.05)$.

Figure 5. The relationship between lettuce head shape and leaf shape index in 2019 and 2020

Based on the NDVI value, we are able to provide information for the vegetation cover of the growing area, which is possibly connected to yield.

The relationship between the NDVI value and the head shape index was evaluated for 5 varieties (Figure 6$)$. In the first year, a significant $(\mathrm{r}=0.750)$ and in the second year a strong $(\mathrm{r}=0.950)$ correlation was detected between these parameters. In both periods, a higher NDVI and head shape index was detected in cos lettuce ('Romaine lettuce'). For iceberg and butterhead lettuce, smaller head shapes were measured in the second year; however, their head weight values were higher, as the head structure became more compact in the second growing season.

Considering other environmental parameters to change the NDVI value: In a lettuce test plant experiment, different irrigation levels were set, and the treatments were determined based on the water holding capacity of the pots. During the development of lettuces, higher NDVI values were measured with higher irrigation level [14]. 


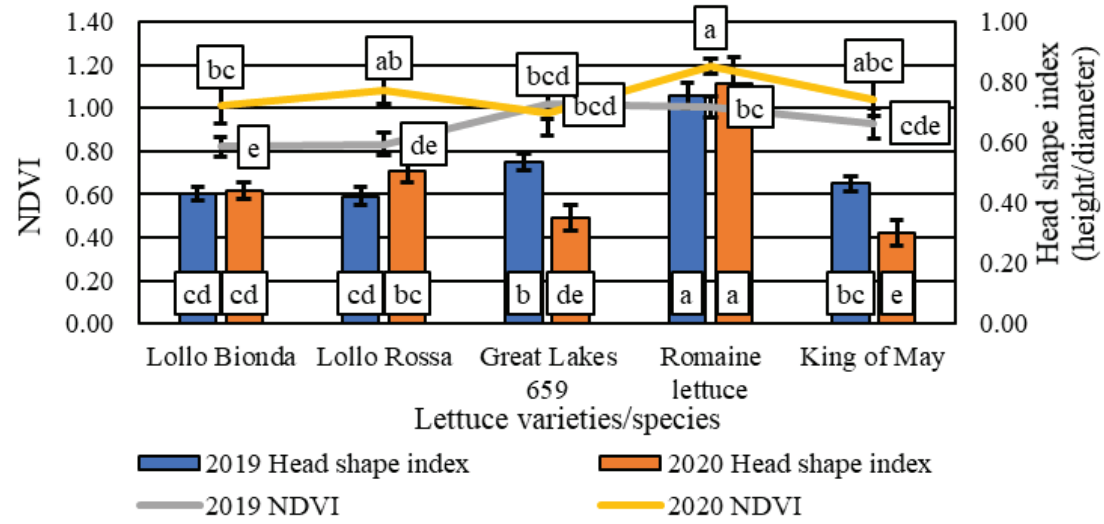

Note: There is no significant difference between the lettuce varieties/types marked with the same letter according to Tukey's test $(\mathrm{P} \leq 0.05)$.

Figure 6. The relationship between lettuce head shape index and NDVI value in 2019 and 2020

Based on the SPAD value, we can also conclude the relative chlorophyll content and the condition of the plants. Statistically, the highest SPAD value was detected for 'Romaine lettuce' (42.87 \pm 1.61 SPAD) and iceberg lettuce (41.77 \pm 1.34 SPAD) in both years (Figure 7). These genotypes also had more intense green leaves, which are referred to as having higher chlorophyll content. While the lowest value (23.66 \pm 0.71 SPAD) of the non-head-forming ones was measured in 'Lollo Bionda', the leaf of this variety also had a reduced green colour intensity. In one study, the SPAD value of lettuces was evaluated at different nitrogen levels at an average temperature of $26{ }^{\circ} \mathrm{C}$. A higher SPAD value (approx. 40-50) was observed at higher nitrogen values (approx. 3.4-3.8\%) [15].

In the case of lettuce, the increased (above-the-limit) nitrate content is one of the quality-reducing parameters, which can be influenced by the variety, the growing season, and the cultivation method. We also measured higher nitrate content for the more intense green leaves than for the light green leaf varieties. However, these values remained below the limit. In both years, the highest nitrate values were measured in 'Romaine lettuce' (565.00 $\pm 49.50 \mathrm{mg} \mathrm{kg}^{-1}$ ) and 'King of May' (542.00 $\pm 31.11 \mathrm{mg} \mathrm{kg}^{-1}$ ), as shown in Figure 8. Probably, these varieties are more sensitive to nitrate accumulation. In the case of the other types, their average nitrate content was $446.33 \pm 24.96 \mathrm{mg} \mathrm{kg}^{-1}$.

Concerning the average of the two years, we found a medium correlation ( $\mathrm{r}$ $=0.540$ ) between SPAD and nitrate content. In one study, the nitrate content of lettuce (for fresh matter basis) was measured in greenhouse spring cultivation (from 8 March to 6 April) on different days after transplanting. The highest value was measured by the continuous supply of nutrients while the lowest when it stopped 10 days before harvest [2]. 


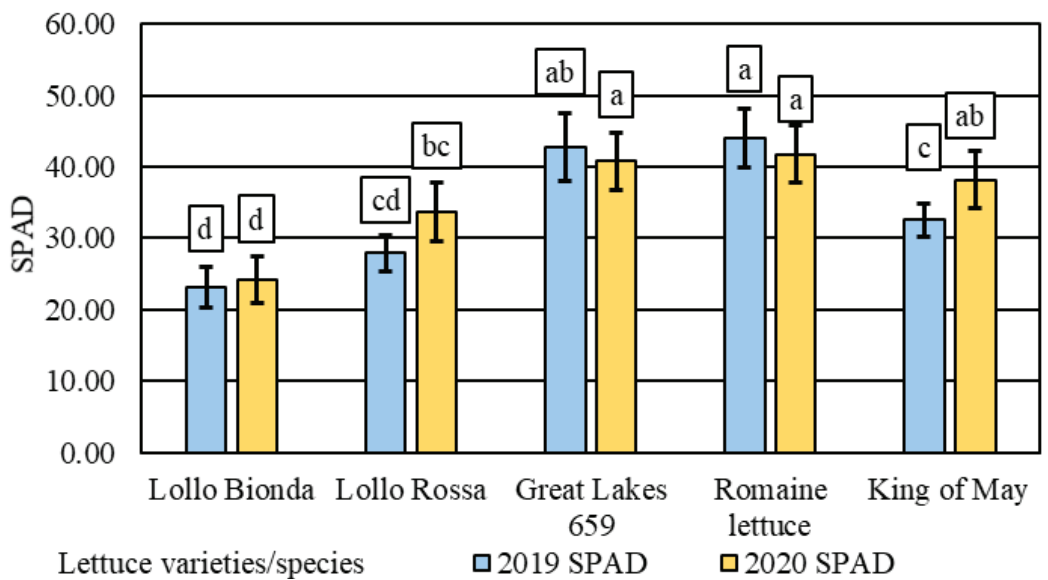

Note: There is no significant difference between the lettuce varieties/types marked with the same letter according to Tukey's test $(\mathrm{P} \leq 0.05)$.

Figure 7. Development of SPAD value for different types of lettuce in 2019 and 2020

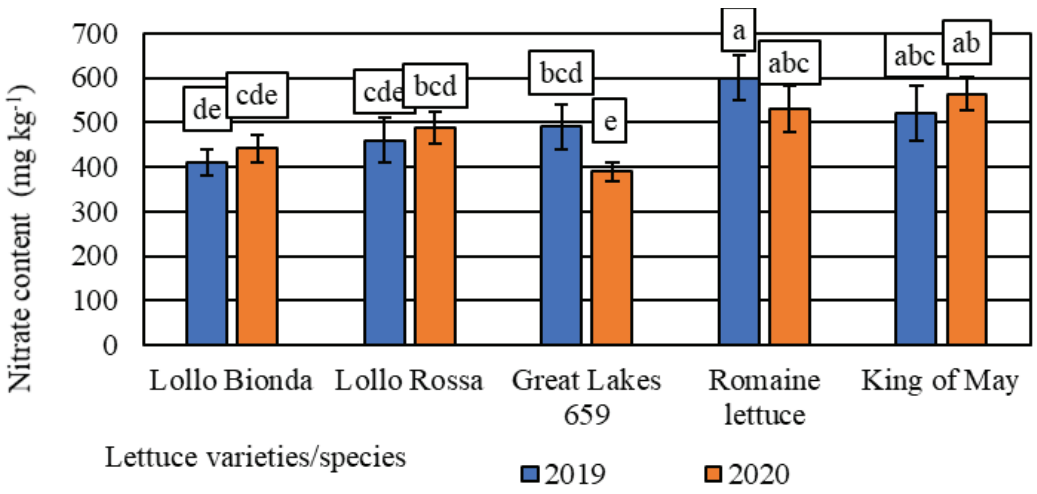

Note: There is no significant difference between the lettuce varieties/types marked with the same letter according to Tukey's test $(\mathrm{P} \leq 0.05)$.

Figure 8. Nitrate content of different types of lettuce in 2019 and 2020

Dry matter content is an important aspect of the shelf life of vegetables. The higher value can ensure the proper quality of vegetables without loss of quality. In the two growing seasons, the highest dry matter content (9.52\%) of the varieties was measured in 'Romaine lettuce', as shown in Figure 9. In the second year, better light conditions had a positive effect on the dry matter content of Lollo types. This period resulted in a much higher increase in dry matter content for these varieties compared to the other lettuce types. 


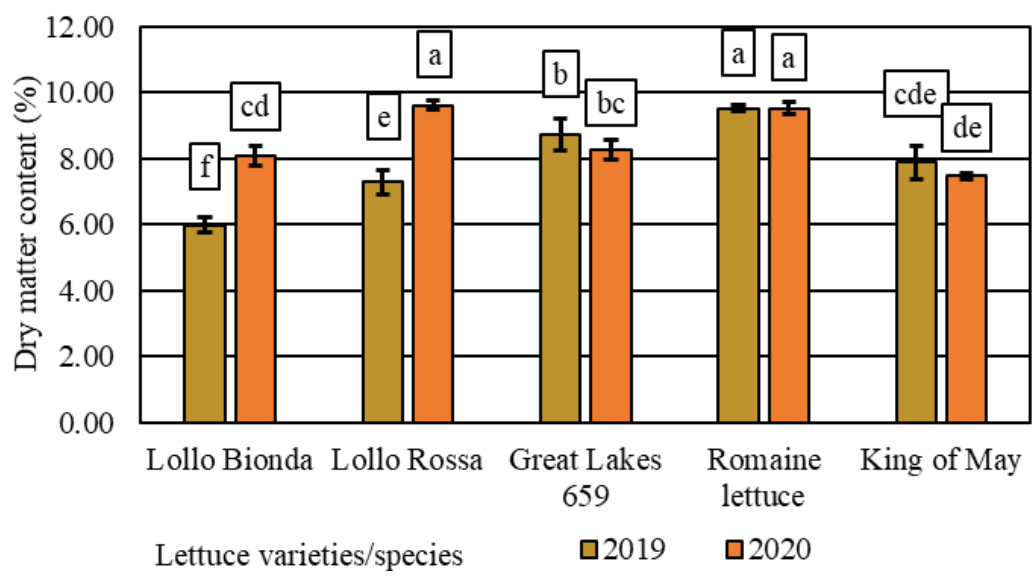

Note: There is no significant difference between the lettuce varieties/types marked with the same letter according to Tukey's test $(\mathrm{P} \leq 0.05)$.

Figure 9. Dry matter content of different types of lettuce in 2019 and 2020

Considering other cultivation technology factors such as fertilization for the development of dry matter content: It was found that the dry matter content of the plants was lower (4.5\%) where the nutrient level had never been reduced. However, when the nutrient replenishments were stopped 10 days before the harvesting, the lettuces had the highest (5.9\%) dry matter content [2]. In our experiment, the dry matter content was higher than those values.

\section{Conclusions}

During the growing season, light conditions can greatly influence the development of the different lettuce types.

Our two-year experiment has proved that different morphological parameters can influence the quality of lettuce. The spherical or oval shape of the head (height/diameter) is preferable for growing because they are less sensitive to soilborne diseases. In our experiment, the iceberg lettuce 'Great Lakes 659' (among the heading types) yielded better quality - higher head weight, dry matter, and lower nitrate content. Among the non-heading types, 'Lollo Bionda' yielded better quality: higher head weight, closed base, and a lower amount of nitrate.

\section{Acknowledgements}

Publishing of this journal is supported by the Institute for Research Programmes of Sapientia Hungarian University of Transylvania. 


\section{References}

[1] Moreira, M. A., Santos, C. A. P. D., Lucas, A. A. T., Bianchini, F. G., Souza, I. M. D., Viégas, P. R. A. (2014), Lettuce production according to different sources of organic matter and soil cover. Agricultural Sciences 5(2), 99-105. http://dx.doi.org/10.4236/as.2014.52013.

[2] Tabaglio, V., Boselli, R., Fiorini, A., Ganimede, C., Beccari, P., Santelli, S., Nervo, G. (2020), Reducing nitrate accumulation and fertilizer use in lettuce with modified intermittent nutrient film technique (NFT) system. Agronomy 10(8), 1208. https://doi.org/10.3390/agronomy10081208.

[3] Zandvakili, O. R., Barker, A. V., Hashemi, M., Etemadi, F., Autio, W. R., Weis, S. (2019), Growth and nutrient and nitrate accumulation of lettuce under different regimes of nitrogen fertilization. Journal of Plant Nutrition 42(14), 1575-1593. https://doi.org/10.1080/01904167.2019.1617313.

[4] Commission Regulation (EU) No 1258/2011 amending Regulation (EC) No $1881 / 2006$ as regards maximum levels for nitrates in foodstuffs. Barross, M. J. (2011), Official Journal of the European Union L 320/17 (last accessed: 06/10/2021). https://eur-lex.europa.eu/LexUriServ/LexUriServ.do?uri=OJ :L:2011:320:0015:0017:EN:PDF.

[5] Tuncay, O. (2011), Relationships between nitrate, chlorophyll and chromaticity values in rocket salad and parsley. African Journal of Biotechnology 10(75), 17152-17159. https://doi.org/10.5897/AJB11.2646.

[6] Zebarth, B. J., Younie, M., Paul, J. W., Bittman, S. (2002), Evaluation of leaf chlorophyll index for making fertilizer nitrogen recommendations for silage corn in a high fertility environment. Communications in Soil Science and Plant Analysis 33(5-6), 665-684. https://doi.org/10.1081/CSS-120003058.

[7] Olfati, J. A., Saadatian, M., Peyvast, G., Malakouti, S. H., Kiani, A., PoorAbdollah, M. (2011), Effect of harvesting date on yield and quality of lettuce. Advances in Environmental Biology 5(7), 1647-1650.

[8] Barg, M., Agüero, M. V., Yommi, A., Roura, S. I. (2009), Evolution of plant water status indices during butterhead lettuce growth and its impact on post-storage quality. Journal of the Science of Food and Agriculture 89(3), 422-429. https://doi.org/10.1002/jsfa.3462.

[9] Pettorelli, N., Ryan, S., Mueller, T., Bunnefeld, N., Jędrzejewska, B., Lima, M., Kausrud, K. (2011), The normalized difference vegetation index (NDVI): Unforeseen successes in animal ecology. Climate Research 46(1), 15-27. https://doi.org/10.3354/cr00936. 
[10] Sun, X., Gao, Y., Lu, Y., Zhang, X., Luo, S., Li, X., Zhao, J. (2021), Genetic analysis of the "head top shape" quality trait of Chinese cabbage and its association with rosette leaf variation. Horticulture Research 8(1), 1-12. https://doi.org/10.1038/s41438-021-00541-y.

[11] Wahab, H. A., Malek, A., Ghobara, M. (2020), Effects of some plant extracts, bioagents, and organic compounds on botrytis and sclerotinia molds. Acta Agrobotanica 73(2). https://doi.org/10.5586/aa.7321.

[12] Gil, M. I., Tudela, J. A., Martínez-Sánchez, A., Luna, M. C. (2012), Harvest maturity indicators of leafy vegetables. Stewart Postharvest Rev. 8(1), 1-9.

[13] Lee, R. J., Bhandari, S. R., Lee, G., Lee, J. G. (2019), Optimization of temperature and light, and cultivar selection for the production of high-quality head lettuce in a closed-type plant factory. Horticulture, Environment, and Biotechnology 60(2), 207-216. https://doi.org/10.1007/s13580-018-0118-8.

[14] Kizil, Ü., Genc, L., Inalpulat, M., Şapolyo, D., Mirik, M. (2012), Lettuce (Lactuca sativa L.) yield prediction under water stress using artificial neural network (ANN) model and vegetation indices. Žemdirbystė = Agriculture 99(4), 409-418.

[15] Mendoza-Tafolla, R. O., Juarez-Lopez, P., Ontiveros-Capurata, R. E., Sandoval-Villa, M., Iran, A. T., Alejo-Santiago, G. (2019), Estimating nitrogen and chlorophyll status of Romaine lettuce using SPAD and at LEAF readings. Notulae Botanicae Horti Agrobotanici Cluj-Napoca 47(3), 751-756. https://doi.org/10.15835/nbha47311589. 